\title{
Impact of Asthma Educational Intervention on Self-Care Management of Bronchial Asthma among Adult Asthmatics
}

\author{
Varalakshmi Manchana1, Rajinder Kaur Mahal2* \\ ${ }^{1}$ School of Medical Sciences, University of Hyderabad, Hyderabad, India \\ ${ }^{2}$ Mohan Dai Oswal Oncology and Research Institute, Oswal College of Nursing, Ludhiana, India \\ Email: varamanchana@gmail.com, ${ }^{*}$ mahalrajinder@yahoo.co.in
}

Received 30 August 2014; revised 30 September 2014; accepted 13 October 2014

Copyright (C) 2014 by authors and Scientific Research Publishing Inc.

This work is licensed under the Creative Commons Attribution International License (CC BY). http://creativecommons.org/licenses/by/4.0/

(c) (7) Open Access

\section{Abstract}

Asthma is one of the most common chronic diseases worldwide [1]. Despite advancement in science and technology and pharmacological revolutions, worldwide asthma prevalence is uncontrolled, morbidity and mortality from asthma. The most common reasons are non adherence to treatment, poor knowledge and skills in disease management [2]. Aim: The study aims to assess the impact of Asthma Education on self care management among Bronchial asthma patients. Objectives: 1) to assess the knowledge on self care management of Bronchial asthma; 2) to develop and administer the Asthma educational intervention on self care management of asthma; 3) to evaluate the impact of Asthma educational intervention on patient knowledge levels in comparison of pre and post test scores. Design: Quasi experimental Pre test-post test design was chosen. Methods: Study was done to assess the effectiveness of structured asthma education program on self care management of Bronchial asthma. Thirty patients, meeting the inclusive criteria, were selected by simple random sampling, and were tested for their knowledge levels on identification of asthma triggers, and warning signs, adherence to specified drugs, diet and breathing exercises. Based on the patient needs, structured education program was developed, validated and administered. Two weeks after administering structured asthma education, post-test was conducted. The Pre-test and Post-test scores were compared to evaluate the effectiveness of the Asthma education. Results: There was significant enhancement on knowledge levels on four areas of assessment and education. After asthma education the knowledge levels on disease process raised from minimum of $10 \%$ in the pre test to $77.50 \%$ in the post test. The knowledge scores on asthma triggers and warning signs enhanced $12 \%$ to $72 \%$. The area of self monitoring and management records a rise in knowledge levels from $20 \%$ minimum scoring in pre test to $82.5 \%$ in the post test. The scores in diet, breathing exercises and adherence to drugs rose from $12.5 \%$ to $72.5 \%$ after asthma education. Conclusion: The findings reveal that educating patients remarkably increased their knowledge

\footnotetext{
"Corresponding author.
} 
levels, which facilitate their behavioral modification thus enhances their self-care. Effective self care management at home level decreases asthma related morbidity and frequent visit to hospitals.

\title{
Keywords
}

\author{
Impact, Asthma Education, Self-Care Management, Adult Asthmatics
}

\section{Introduction}

"When you can't breathe, nothing else matters", is the mantra of the American lung Association. Asthma is one of the most common chronic diseases worldwide [1]. There is a noticeable increase in health care burden from asthma in several areas of the world [3]. It occurs in every sector of the society and all countries regardless of the level of development and it is more common in affluent populations. The prevalence may be related to environmental factors, exposure to allergens, pollutants and urbanization. Much of the morbidity from asthma is believed to be due to factors such as denial of having a chronic condition [4] [5]. Asthma due to its effects on bronchial passage compromises the respiration and intern effects physical and psycho-social aspects of life and impairs the quality of life. The importance of emotional factors and restriction on social life may be greater when symptoms are not adequately controlled. Asthma patients may not completely appreciate the impact of the disease on their social life and claim they lead a normal life or mask their restrictions, wanting to "live like others”. It leads to great impact on their performance either at school or work area.

The international patterns of asthma prevalence are not explained by the current knowledge of the causation of asthma. Research in to the causation of asthma and the efficiency of the primary and secondary intervention strategies represent key priority areas in the field of asthma research. The rate of asthma increases as communities adopt western life styles and become urbanized with the projected increase in the proportion [6]. Inadequate asthma control may be due to poor knowledge of the disease process and medication use, poor understanding of the use of inhalers and poor self-management [7]-[9]. Asthma, being one of the commonest non-communicable diseases, affects a total of 300 million worldwide [10] [11]. Mortality rates are more prevalent in lower socio economic groups [12]. Around $8 \%$ of the Swiss population suffers from asthma and there are an estimated 4 million asthmatics in Germany. In Western Europe as a whole, asthma has doubled in ten years, according to the UCB Institute of Allergy in Belgium. In the United States, the number of asthmatics has leapt by over $60 \%$ since the early 1980s and deaths have doubled to 5000 a year. There are about 3 million asthmatics in Japan of whom $7 \%$ have severe and 30\% have moderate asthma. In Australia, one child in six under the age of 16 is affected [6] [13]. India has an estimated number of 15 - 20 million asthmatics and a large number of them are from cities like Hyderabad. $80 \%$ of asthmatics suffer from Allergic Rhinitis. Despite a great availability of specific drugs and improvement in technology, prevalence of asthma is still increasing. Using a positive family history of asthma could provide a basis for targeted prevention efforts, aimed at reducing exposure to environmental risk factors [14]. Though it is a manageable condition, the suffering of asthma patients is not in control. The reasons may be many, but mainly due to inadequate health communication, patients' unawareness of the disease process, preventive measures to avoid acute attacks, and the measures to be adapted for effective maintenance at home [15] [16]. Current level of asthma management and control fall short of international guidelines for asthma management.

\subsection{Background}

Asthma is a serious global health problem with increasing prevalence worldwide [17]. The population prevalence of asthma reported in different field studies varies and ranges from $2.4 \%-6.4 \%$ and higher prevalence rates have been reported among school children. According to national family health survey (NFHS-3), the overall prevalence of asthma among adult men and women in India are 1696 and 1627 per 10,000 population respectively. Management of Asthma becomes suboptimal due to poor adherence to evidence-based guidelines and under-diagnosis. Non adherence and non-compliance to therapeutic regimens are a constant challenge to nurses and other health professionals. Prabhakaran et al. (2006) reported that well-structured asthma education with reinforcing by the health care professionals is the key to achieve effective self-care management of asthma. Thapar A, et al. (1994), insisted on patient education as an important part of asthma management. Structured 
asthma education tailored to the patient needs on self- care management improves adherence with inhaler devices and self monitoring. If patients understand the risks of non-compliance and benefits of compliance and believes the treatment is safe, it will increase their motivation and confidence to improve their self-management practices [18] [19]. Prabhakaran et al. (2006) defined non-compliance as the failure to take treatment as agreed upon by the patient and health care professionals. Effective asthma management should include positive control over asthma symptoms and its acute exacerbations and improved quality of living. Hence providing right knowledge on self-monitoring and adherence to medications, proper dietary measures and breathing exercises promotes the disease control and reduces suffering due to frequency of acute attacks.

\subsection{Aim}

The study aims to assess the impact of Asthma Education on asthma knowledge related to self care management among Bronchial asthma patients.

\subsection{Objectives}

1) To assess the knowledge on self care management of Bronchial asthma.

2) To develop and administer the Asthma educational intervention on self care management of asthma.

3) To evaluate the impact of Asthma educational intervention.

4) To associate the knowledge scores with the demographic variables.

\section{Methodology}

A Quasi experimental, Pre-Post test single group design was chosen for the study to assess the effectiveness of the Asthma educational program on knowledge regarding home management of asthma. Thirty patients, meeting the inclusive criteria with confirmed diagnosis for Bronchial asthma attending inpatient and outpatient units of a Government Hospital for General and Chest diseases, who were on inhaler therapy and willing to participate in the study were selected by simple random sampling. They were tested for their knowledge levels on identification of asthma triggers, and warning signs, adherence to specific drugs, diet and breathing exercises. Based on the patient needs, structured education program was developed and validated. Asthma education program was administered among the study group irrespective of their pretest knowledge scores and its effectiveness was tested by administering the same questionnaire in the posttest.

$\mathrm{O} 1 \quad \mathrm{X} \quad \mathrm{O} 2$

Two weeks after administering structured asthma education, post test was conducted.

The Asthma Educational Intervention was divided in to four sections;

Section I: Includes the information on the disease process, signs and symptoms

Section II: Includes the information on asthma triggers, warning signs

Section III: Preventive measures for asthma trigger exposure and acute attacks by self-monitoring

Section IV: Includes information on adherence to drugs, dietary practices and breathing exercises.

The Pre-test and Post-test scores were compared to evaluate the effectiveness of the Asthma education.

The tool was validated by the experts in Nursing, Medicine and Statistics.

The reliability of the tool was obtained by the Test-retest method. The subject's first and repeated scores were compared by Coefficient of correlation method. A value of $r=0.96$ was obtained, indicating the reliability of the tool.

\subsection{Inclusion Criteria}

- Individuals diagnosed with Bronchial asthma and between the age group of 21 to 60 years

- Asthma patients who knows Telugu and/or Hindi and/or English languages.

- Patients with confirmed diagnosis of Bronchial asthma, on inhalers, attending inpatient and outpatient units of Government General and Chest Hospital, Hyderabad.

\subsection{Exclusion Criteria}

- Patients who are not willing to participate in the study.

- Patients who are with other chronic medical conditions involving breathing difficulties. 
Ethical approval was secured from the institution. Written informed consent was taken from the participants.

\section{Results}

The findings shows that $10(33.33 \%)$ were in the age group of 21 - 30 years, 7(23.33\%) were in the age group of 31 - 40 years and $8(26.67 \%)$ were in the group of 41 - 50 years and $5(16.67 \%)$, in 51 - 60 years age group. With regard to religion 19 patients (63.33\%) were Hindus, 5 (16.66\%) are Christians and 6 (20\%) were Muslims and none in others. With regard to marital status 25 (83.33\%) patients were married, 3 (10\%) of them were divorced/separated, widow/widower and $2(6.66 \%)$ were unmarried/single. With regard to type of family six patients (20\%) come from nuclear family, 15 (50\%) come from joint family, nine (30\%) come from extended family. With regard to educational status twelve (40\%) patients were illiterates, $9(30 \%)$ were having primary education, $5(17 \%)$ were having secondary education and $4(13 \%)$ of them were having graduation and above. In regard to occupation, maximum of $33.33 \%$ were skilled workers and a minimum of $6.67 \%$ were unemployed and $17 \%$ were laborers and $20 \%$ were in to business.

Part II: With regard to the knowledge regarding identifying measures taken to avoid triggers 13 (43.33\%) have below average level of knowledge, 17 (56.66\%) have average level of knowledge and none of them have above average level of knowledge.

With regard to the knowledge regarding identifying the warning signs of asthma and measures taken to prevent acute attack of asthma 18 patients (60\%) have below average level of knowledge, 11 (36.66\%) have average level of knowledge, one (3.33\%) have above average level of knowledge. With regard to knowledge regarding regular medications, 16 (53.33\%) patients have below average level of knowledge, 13 (43.33\%) have average level of knowledge, 1 (3.33\%) have above average level of knowledge. With regard to over all knowledge regarding home management of asthma, 17 (56.66\%) patients have below average level of knowledge, 13 (43.33\%) have average level of knowledge and none of them have above average level of knowledge.

After the implementation of the Asthma education, the post test scores are remarkably enhanced in all the four areas. After asthma education the knowledge levels on disease process raised from minimum of $10 \%$ in the pre test to $77.50 \%$ in the post test. The knowledge scores on asthma triggers and warning signs enhanced $12 \%$ to $72 \%$. The area of self monitoring and management records a rise in knowledge levels from $20 \%$ minimum scoring in pre test to $82.5 \%$ in the post test. The scores in diet, breathing exercises and adherence to drugs rose from $12.5 \%$ to $72.5 \%$ after asthma education.

Association between the demographic variables and the level of knowledge on home management of asthma: The data was analyzed with the help of descriptive statistics. The data regarding the association between demographic variables and knowledge scores has done by frequency and percentage analysis for each group. The result shows that there is no significant association between demographic variables and knowledge on home management of asthma.

\section{Major Findings of the Study}

Figure 1 shows that 10 (33.33\%) were in the age group of 21 - 30 years, 7 (23.33\%) were in the age group of 31 - 40 years, eight and five in the group of 41 - 50 years and 51 - 60 years respectively

With regard to Gender17 patients (56.676\%) were males and 13 (43.33\%) were female gender (Figure 2).

With regard to educational status twelve (40\%) patients were illiterates, 9 (30\%) were having primary education, 5 (17\%) were having secondary education and $4(13 \%)$ of them were having graduation and above (Figure 3$)$.

Table 1 indicates maximum of $33.33 \%$ were skilled workers and a minimum of $6.67 \%$ were unemployed and $17 \%$ were laborers and $20 \%$ were in to business.

Figure 4 indicates that after administering the asthma education, patient perception and practice towards symptom management is enhanced, which is indicated by reduction in the frequency of symptom experience from $53 \%$ of them who experienced more than once in a week in pre test were $0 \%$ in the post test. Symptom experienced less than once a week were $10 \%$ in pre test, it was recorded above $50 \%$ in the post test, indicating towards symptom control.

Table 2 shows that out of 30 patients, majority (56.66\%) patients have average level of knowledge and 43.33\% have below average level of knowledge regarding disease process and symptom identification in the pre test, which was enhanced to 63.33 in the above average level, 36.66 were in the average level knowledge and none were in below the average category. 


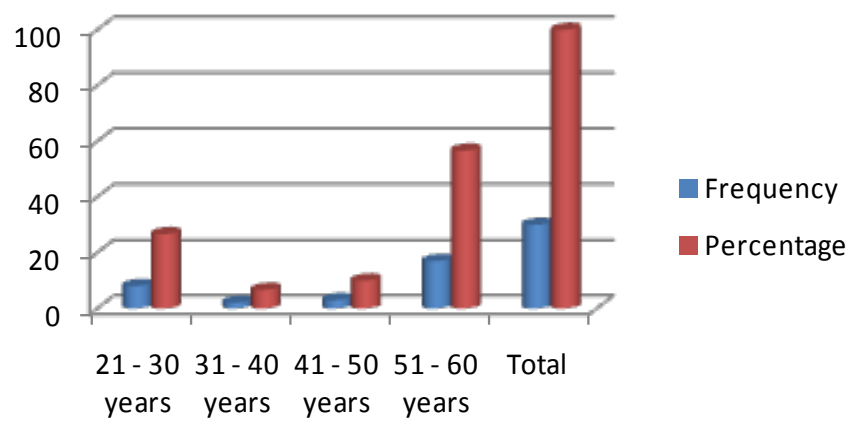

Figure 1. Frequency and percentage distribution of asthma patients according to age.

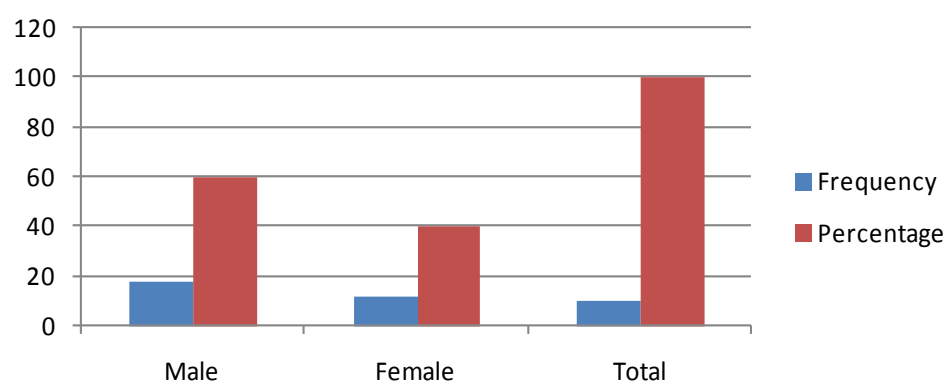

Figure 2. Frequency and percentage distribution of asthma patients according to gender.

\section{Education}

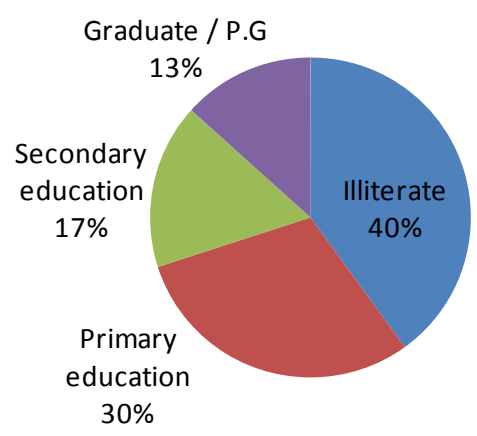

Figure 3. Frequency and percentage distribution of asthma patients according to education.

Frequency ot symptom experience

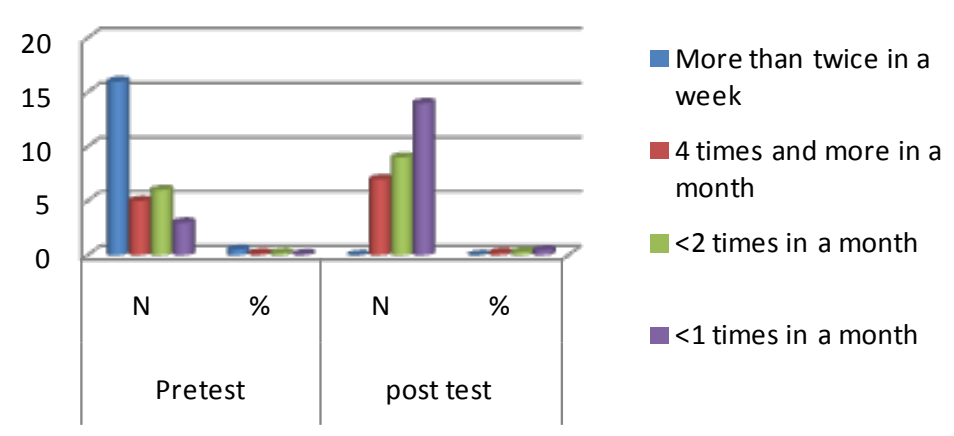

Figure 4. Frequency and percentage distribution of asthma symptom experience for the past six months. 
Table 1. Frequency and percentage distribution of asthma patients according to occupation.

\begin{tabular}{cccc}
\hline S.No & Occupation & Frequency & Percentage (\%) \\
\hline 1 & Unemployed & 2 & 6.67 \\
2 & Laborer & 5 & 17 \\
3 & Skilled & 10 & 33.33 \\
4 & Business & 6 & 20 \\
5 & Professional & 7 & 23.33 \\
\hline
\end{tabular}

Table 2. Frequency and percentage distribution of knowledge related to identifying measures to avoid triggers.

\begin{tabular}{ccrccc}
\hline & \multicolumn{2}{c}{ Pre-test } & \multicolumn{2}{c}{ Post-test } \\
\cline { 2 - 5 } Knowledge on asthma disease process & $\mathrm{n}$ & $\%$ & $\mathrm{n}$ & $\%$ \\
Below average & 13 & 43.33 & - & 36.66 \\
Average & 17 & 56.66 & 11 & 19 & 63.33 \\
\hline
\end{tabular}

Table 3 presented below shows the Frequency and Percentage Distribution of Knowledge of Asthma Patients regarding Identifying Warning Signs of Asthma triggers; 60\% of them were in below average levels in the pre test, which was recorded nil in the post test. The average levels are $36.66 \%$ and $3.33 \%$ were in the above average levels in the pre test, which were enhanced to $73.33 \%$ in the above average in the post test, after receiving the asthma education.

Table 4 scores indicate knowledge enhancement after the asthma education, 53.33\% in the below average have become nil and $70 \%$ of them were in the above average in the post test distribution.

Table 5 indication knowledge enhancement of the subjects in the area of awareness on medications, diet and breathing exercises, was indicative of positive shift of knowledge by $66.66 \%$ in the above average category and only $3 \%$ in the below average group.

Figure 5 indicates the minimum percentage scores in pre test was 42.50 , which has enhanced to 82.50 , the percentage scores in post test were all in the above average, with scores distributed from $82.50 \%$ to $100 \%$.

The knowledge distribution in Table 6 in Pre test and Post test scores indicate the rise in knowledge levels ranging from minimum of $10 \%$ to maximum $100 \%$ and the post test scores reveal the knowledge enhancement in all the four areas of the study to above average scores.

In all the four areas calculated "t” values are higher than the table "t" value. Thus the Pre-Post test knowledge scores difference and significance on home managementis vivid in the study (Table 7).

The findings revealed a significant difference in the pre and post test scores. After administering the asthma education on self care management of bronchial asthma, the results have shown that the obtained " $t$ " value for knowledge is highly significant. The null hypothesis was rejected because there is a significant difference in the pretest and posttest scores (Figure 6).

\section{Discussion}

A multicentric study (Aggarwal, A.N., et al., 2006), gives an insight in to relationship of respiratory symptoms, atopy and asthma with several independent causal factors. The rate of asthma increases as communities adopt western lifestyles and become urbanized with the projected increase in the disease proportion [20] [21]. V. Singh et al. (2002) emphasized on the importance of communication skills and stated the inadequacy of effective communication skills among physicians [22]. The study revealed that only $2 \%$ of physicians were graded as convincing, $15.6 \%$ were just convincing and $82.4 \%$ were not convincing. Effective asthma management should include positive control over asthma, which requires adequate emphasis on patient education and positive attitude and knowledge among health care professionals. The study was conducted on 30 clients who were attending the in/out patient units of Government general and chest hospital. Data collection was done with the help of structured 
Table 3. Frequency and percentage distribution of knowledge related to identifying asthma triggers and warning signs.

\begin{tabular}{|c|c|c|c|c|}
\hline \multirow{2}{*}{ Knowledge on asthma triggers and warning signs } & \multicolumn{2}{|c|}{ Pre-test } & \multicolumn{2}{|c|}{ Post-test } \\
\hline & $\mathrm{n}$ & $\%$ & $\mathrm{n}$ & $\%$ \\
\hline Below average & 18 & 60 & - & - \\
\hline Average & 11 & 36.66 & 8 & 26.66 \\
\hline Above average & 1 & 3.33 & 22 & 73.33 \\
\hline
\end{tabular}

Table 4. Frequency and percentage distribution of the level of knowledge regarding self monitoring, preventive measures of asthma.

\begin{tabular}{ccccc}
\hline \multirow{2}{*}{ Knowledge on Preventive measures and self monitoring } & \multicolumn{2}{c}{ Pre-test } & \multicolumn{2}{c}{ Post-test } \\
\cline { 2 - 5 } & $\mathrm{n}$ & $\%$ & $\mathrm{n}$ & $\%$ \\
\hline Below average & 16 & 53.33 & - & - \\
Average & 13 & 43.33 & 9 & 30 \\
Above average & 1 & 3.33 & 21 & 70 \\
\hline
\end{tabular}

Table 5. Frequency and Percentage distribution of the level of knowledge regarding adherence to medications and diet and breathing exercises.

\begin{tabular}{cccccc}
\hline \multirow{2}{*}{ Knowledge on Diet, adherence to drugs and breathing exercises } & \multicolumn{2}{c}{ Pre-test } & \multicolumn{2}{c}{ Post-test } \\
\cline { 2 - 5 } & & $\mathrm{n}$ & $\%$ & $\mathrm{n}$ & $\%$ \\
Below average & 17 & 56.66 & 1 & 3.33 \\
Average & 13 & 43.33 & 9 & 30 \\
Above average & - & - & 20 & 66.66 \\
\hline
\end{tabular}
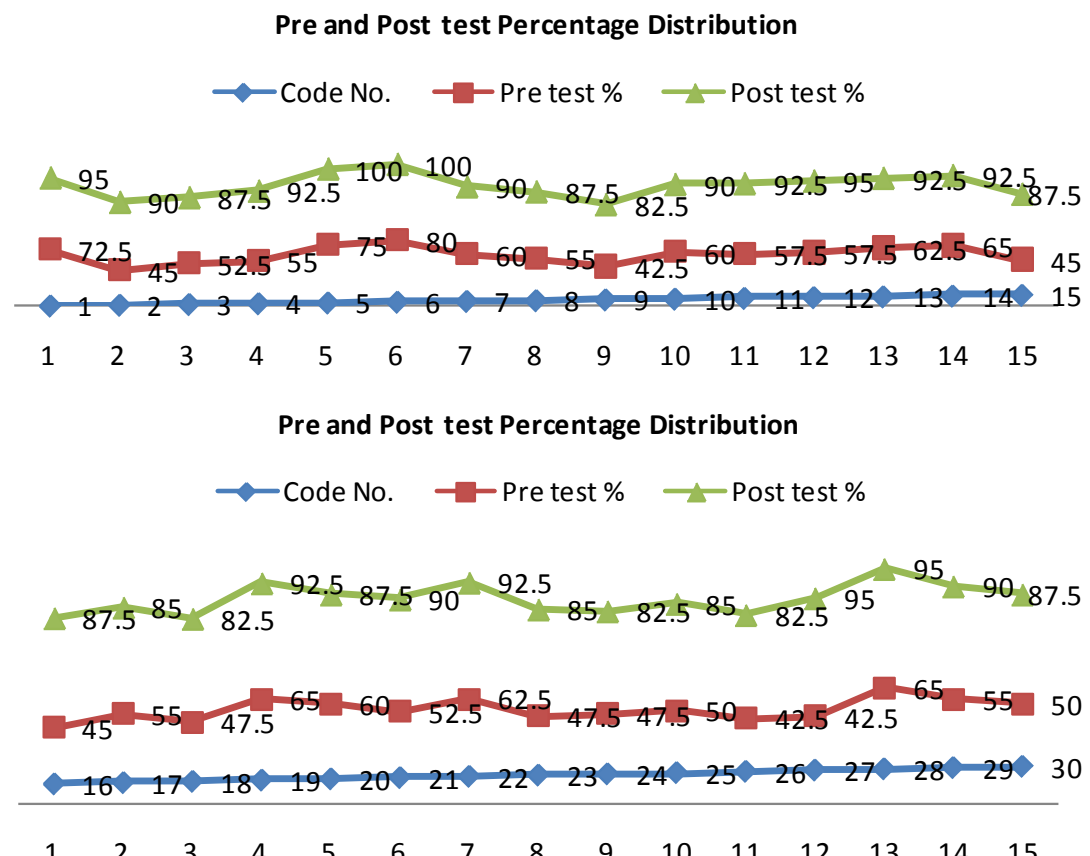

Figure 5. Pre- and post-test knowledge distribution. 
Table 6. Distribution of pre-test and post-test frequency and percentages of knowledge scores; $\mathrm{N}=30$.

\begin{tabular}{|c|c|c|c|c|}
\hline \multirow[t]{2}{*}{ Code No } & \multicolumn{2}{|c|}{ Pre-test } & \multicolumn{2}{|c|}{ Post-test } \\
\hline & $\mathrm{n}$ & $\%$ & $\mathrm{n}$ & $\%$ \\
\hline 1 & 27 & 67.50 & 38 & 95.00 \\
\hline 2 & 18 & 45.00 & 36 & 90.00 \\
\hline 3 & 21 & 52.50 & 35 & 87.50 \\
\hline 4 & 9 & 22.50 & 30 & 75.00 \\
\hline 5 & 16 & 40.00 & 40 & 100.00 \\
\hline 6 & 15 & 37.50 & 32 & 80.00 \\
\hline 7 & 5 & 12.5 & 29 & 72.50 \\
\hline 8 & 22 & 55.00 & 35 & 87.50 \\
\hline 9 & 4 & 10.00 & 31 & 77.50 \\
\hline 10 & 22 & 55.00 & 36 & 90.00 \\
\hline 11 & 20 & 50.00 & 37 & 92.50 \\
\hline 12 & 19 & 47.50 & 38 & 95.00 \\
\hline 13 & 13 & 32.50 & 37 & 92.50 \\
\hline 14 & 16 & 40.00 & 37 & 92.50 \\
\hline 15 & 10 & 25.00 & 35 & 87.50 \\
\hline 16 & 10 & 25.00 & 35 & 87.50 \\
\hline 17 & 12 & 30.00 & 34 & 85.00 \\
\hline 18 & 9 & 22.50 & 33 & 82.50 \\
\hline 19 & 16 & 40.00 & 37 & 92.50 \\
\hline 20 & 14 & 35.00 & 35 & 87.50 \\
\hline 21 & 21 & 52.50 & 36 & 90.00 \\
\hline 22 & 27 & 67.50 & 40 & 100.00 \\
\hline 23 & 19 & 47.50 & 34 & 85.00 \\
\hline 24 & 8 & 20.00 & 33 & 82.50 \\
\hline 25 & 20 & 50.00 & 34 & 85.00 \\
\hline 26 & 17 & 42.50 & 33 & 82.50 \\
\hline 27 & 13 & 32.5 & 38 & 95.00 \\
\hline 28 & 12 & 30 & 38 & 95.00 \\
\hline 29 & 12 & 30 & 36 & 90.00 \\
\hline 30 & 10 & 25 & 35 & 87.50 \\
\hline
\end{tabular}

Table 7. Test of significance showing the difference in pre- and post-test knowledge scores $\mathrm{N}=30$.

\begin{tabular}{|c|c|c|c|c|c|c|}
\hline S.NO & Areas of knowledge & Pre- and post-test knowledge score difference & Mean & S.D & SEM & " $\mathrm{t}$ " test value \\
\hline 1 & Identifying asthma triggers & 117 & 3.9 & 1.18 & 0.215 & 18.13 \\
\hline 2 & Identifying warning signs & 136 & 4.5 & 1.28 & 0.23 & 19.56 \\
\hline 3 & Preventive measures & 83 & 2.8 & 1.22 & 0.22 & 12.72 \\
\hline 4 & $\begin{array}{l}\text { Adherence to specific drugs, } \\
\text { diet and exercises }\end{array}$ & 72 & 2.4 & 1.45 & 0.26 & 9.23 \\
\hline
\end{tabular}




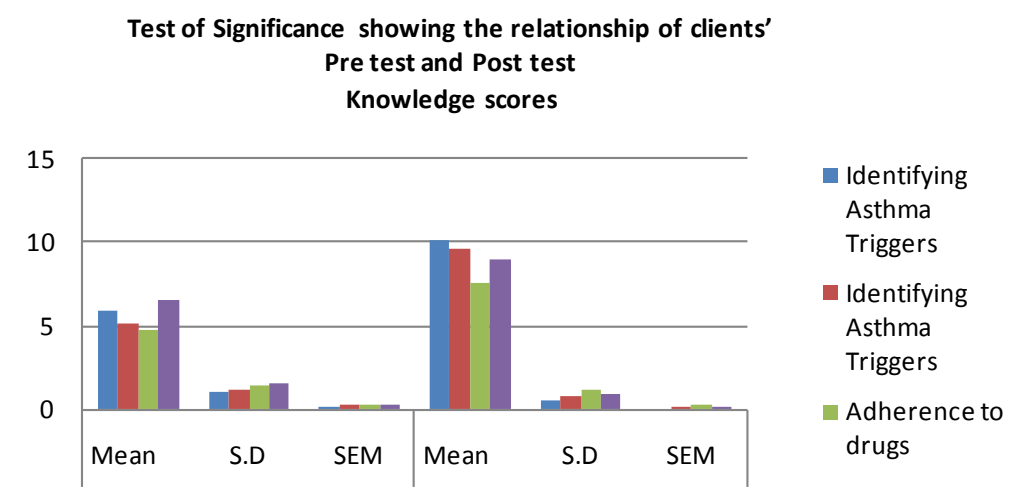

Figure 6. Test of significance showing the relationship of clients' pre-test and post-test knowledge scores.

interviewer assisted questionnaire and the data was analyzed with the help of descriptive and inferential statistics. In the present study, at In Area 1: At 5\% level of significance with degrees of freedom (df) 29, the table value of " $\mathrm{t}$ " is 1.699, which is less than the calculated value of " $t$ ". 18.13. In Area 2: At 5\% level of significance with degrees of freedom (df) 29, the table value of "t" is 1.699, which is less than the calculated value of " $\mathrm{t}$ ". 19.56. At Area 3: At $5 \%$ level of significance with degrees of freedom (df) 29, the table value of " $t$ " is 1.699, which is less than the calculated value of "t". 12.72. In Area 4: At 5\% level of significance with degrees of freedom (df) 29, the table value of " $\mathrm{t}$ " is 1.699, which is less than the calculated value of " $\mathrm{t}$ ". 9.23. Which is higher than the table value; hence, there is significant difference in knowledge before and after the planned educational intervention. $\mathrm{P}<0.05$.

The relationship between patients' knowledge to age and gender in pre test shows that the age group ranges from 21 - 60 years. Among men 11 are with average scores, equally to women. Seven men and only one woman are in the above average group. In the post test; all 17 men and 13 women are in the above average group. The relation with knowledge and education in the pretest reveals that 22 clients were in the average group and eight in the above average group; two were unemployed in the average group and eight were in the above average group. In the post test, irrespective of education and occupation, total 30 were in the above average group.

The present study assesses the effectiveness of educational intervention on the clients' knowledge regarding self-care management of bronchial asthma. The findings indicate that educational intervention was an effective method of influencing knowledge of the subjects, thus aids in behavior modification and enhancing self control over the disease condition. Usually, asthma patients on their diagnosis and follow up visits were not provided with adequate information on disease process, symptom and trigger identification, preventive measures and proper self-care monitoring of disease control and self-care management. If patients understand the risks of non-compliances and the benefits of compliance, and believe the treatments are safe, it will increase their motivation and confidence to improve their self-management practices. The study concludes that adequate patient education is the key to successful and effective asthma management.

\section{Limitations and Recommendations}

Retention of information might be greater if follow up reinforcement would be enhanced for a period of 6 months and 12 months. A realistic control of symptoms cannot be achieved unless the patient maintains on appropriate regimen with regard to medication order. Hence a long term follow-up study with bigger sample would be more advantageous in asthma research.

\section{Conclusions}

The following conclusions were drawn based on the findings of the study:

1) There is significant difference in the pre-test and post-test knowledge scores, which show that exposure to educational intervention has significant effect in improving the individual subject's knowledge.

2) Irrespective of education, gender, occupation and age, clients were interested to learn about home management of bronchial asthma. 
Present study shows that the knowledge level of asthma patients regarding the self care management of asthma shows that there was a significant raise in the overall performance, which shows that exposure to structured asthma education on knowledge and practices further motivate and bring modifications in the behavior of the individuals, which can be utilized to get control over asthma and to reduce frequency of acute attacks.

\section{Acknowledgements}

The authors wish to acknowledge the support of the Medical and Nursing superintendent of the Government General and Chest Hospital and Golconda area hospital for their support in lending permission and in conducting the study and would extend special appreciation to all the study participants, who participated in the study.

\section{Funding Statement}

This research received no specific grant from any funding agency in the public, private or non-profit sectors.

\section{Conflicts of Interest}

No Conflict of interest has been declared by the authors.

\section{References}

[1] Aggarwal, A.N., Chaudhry, K., Chhabra, S.K., et al. (2006) Prevalence and Risk Factors for Bronchial Asthma in Indian Adults: A Multicenter Study. Indian Journal of Chest Diseases and Allied Sciences, 48, 13-22.

[2] Braido, F., Brusselle, G., et al. (2013) International Cross Sectional and Longitudinal Assessment on Asthma Control in European Adult Patients-The LIASON Study Protocol. BMC Pulmonary Medicine, 13, 8. http://www.biomedcentral.com/1471-2466/13/8

[3] Wilson, B.R., Seamagar, P., German, D.F., et al. (1993) A Controlled Trial of Two Forms of Self Management Education for Adults with Asthma. The American Journal of Medicine, 94, 564-576. http://dx.doi.org/10.1016/0002-9343(93)90206-5

[4] Gibson, P.G., Powell, H., Wilson, A., Hensley, M.J., Abramson, M.J., Bauman, A., Walters, E.H. and Roberts, J.J.L. (2002) Limited (Information Only) Patient Education Programs for Adults with Asthma (Review). http://onlinelibrary.wiley.com/book/10.1002/14651858

[5] Thapar, A. (1994) Educating Asthmatic Patients in Primary Care a Pilot Study of Small Group Education. Family Practice, 11, 39-43. http://dx.doi.org/10.1093/fampra/11.1.39

[6] Masoli, M., Fabian, D., Holt, S. and Bearley, S. (2004) Global Burden of Asthma, Developed for the Global Initiative for Asthma (GINA). Allergy, 59, 469-478.

[7] Prabhakaran, L., Lim, G., Abhisheganade, J., Chee, C.B.E. and Choo, Y.M. (2006) Impact of an Asthma Education Programme on Patients Knowledge, Inhaler Technique and Compliance to Treatment. Singapore Medical Journal, 47, 225-231.

[8] Hilton, S., Sibbald, B., Anderson, H. and Freeling, P. (1986) Controlled Evaluation of the Effects of Patients Education on Asthma Morbidity in General Practice. The Lancet, 4, 26-29. http://dx.doi.org/10.1016/S0140-6736(86)91904-5

[9] Lai, C.K.W., De Guia, T.S., Kim, Y.Y., et al. (2002) Asthma Control in the Asia-Pacific Region. The Asthma Insights and Reality in Asia Pacific Study. Journal of Allergy and Clinical Immunology, 111, 263-268. http://dx.doi.org/10.1067/mai.2003.30

[10] Rabe, K.F., Adachi, M., Lai, C.K., Soriano, J.B., Vermeire, P.A., Weiss, K.B. and Weiss, S.T. (2004) Worldwide Severity and Control of Asthma in Children and Adults: The Global Asthma Insights and Reality Surveys. Journal of Allergy and Clinical Immunology, 114, 40-47.

[11] Global Global Strategy for Asthma Management and Prevention (2007) Global Initiative for Asthma (GINA). http://www.ginasthma.org

[12] Evans, G.W. and Kantrowitz, E. (2002) Socioeconomic Status and Health: The Potential Role of Environmental Risk Exposure. Annual Review of Public Health, 23, 303-331. http://dx.doi.org/10.1146/annurev.publhealth.23.112001.112349

[13] Liu, A.H., Gilsenan, A.W., Stanford, R.H., Lincourt, W., Ziemiecki, R. and Ortega, H. (2010) Status of Asthma Control in Pediatric Primary Care: Results from the Pediatric Asthma Control Characteristics and Prevalence Survey Study (ACCESS). The Journal of Pediatrics, 157, 276-281. http://dx.doi.org/10.1016/j.jpeds.2010.02.017

[14] Burke, W., Fesinmeyer, M., Reed, K., et al. (2003) Family History as a Predictor of Asthma Risk. American Journal of Preventive Medicine, 24, 160-169. http://dx.doi.org/10.1016/S0749-3797(02)00589-5

[15] Elder, W., Ege, M.J. and von Mutius, E. (2006) The Asthma Epidemic. The New England Journal of Medicine, 355, 2226-2235. http://dx.doi.org/10.1056/NEJMra054308 
[16] Evans, G.W. and Kantrowitz, E. (2002) Socioeconomic Status and Health: The Potential Role of Environmental Risk Exposure. Annual Review of Public Health, 23, 303-331. http://dx.doi.org/10.1146/annurev.publhealth.23.112001.112349

[17] GINA Report (2012) Global Strategy for Asthma Management and Prevention. http://www.ginaasthma.org/2011

[18] Bousquet, J., Bousquet, P.J., Godard, P. and Davers, J.P. (2005) The Public Health Implications of Asthma. Bulletin of the World Health Organization, 83, 548-554.

[19] Scherer, Y.K. and Bruce, S. (2001) Knowledge, Attitudes and Self-Efficiency and Compliance with Medical Regimen, Number of Emergency Department Visits and Hospitalization in Adults with Asthma. Heart \& Lung, 30, 250-257. http://dx.doi.org/10.1067/mhl.2001.116013

[20] Moldefsky, H., Broder, I. Davies, G. and Leznoff, A. (1979) Videotape Educational Program for People with Asthma. Canadian Medical Association Journal, 120, 669-672.

[21] Stanford, R.H., Gilsenan, A.W., Ziemiecki, R., Zhou, X., Lincourt, W.R., Ortega, H. (2010) Predictors of Uncontrolled Asthma in Adult and Pediatric Patients: Analysis of the Asthma Control Characteristics and Prevalence Survey Studies (Access). Journal of Asthma, 47, 257-262. http://dx.doi.org/10.3109/02770900903584019

[22] Singh, V., Khandelwal, R., Bohra, S., Gupta, R. and Gupta, B.S. (2002) Evaluation of Communication Skills of Physicians about Asthma. Journal of the Association of Physicians of India, 50, 1266-1269. 
Scientific Research Publishing (SCIRP) is one of the largest Open Access journal publishers. It is currently publishing more than 200 open access, online, peer-reviewed journals covering a wide range of academic disciplines. SCIRP serves the worldwide academic communities and contributes to the progress and application of science with its publication.

Other selected journals from SCIRP are listed as below. Submit your manuscript to us via either submit@scirp.org or Online Submission Portal.
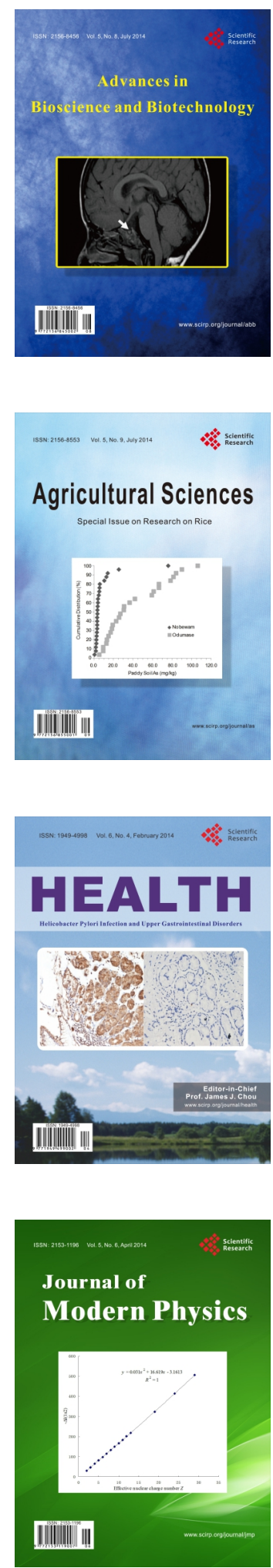
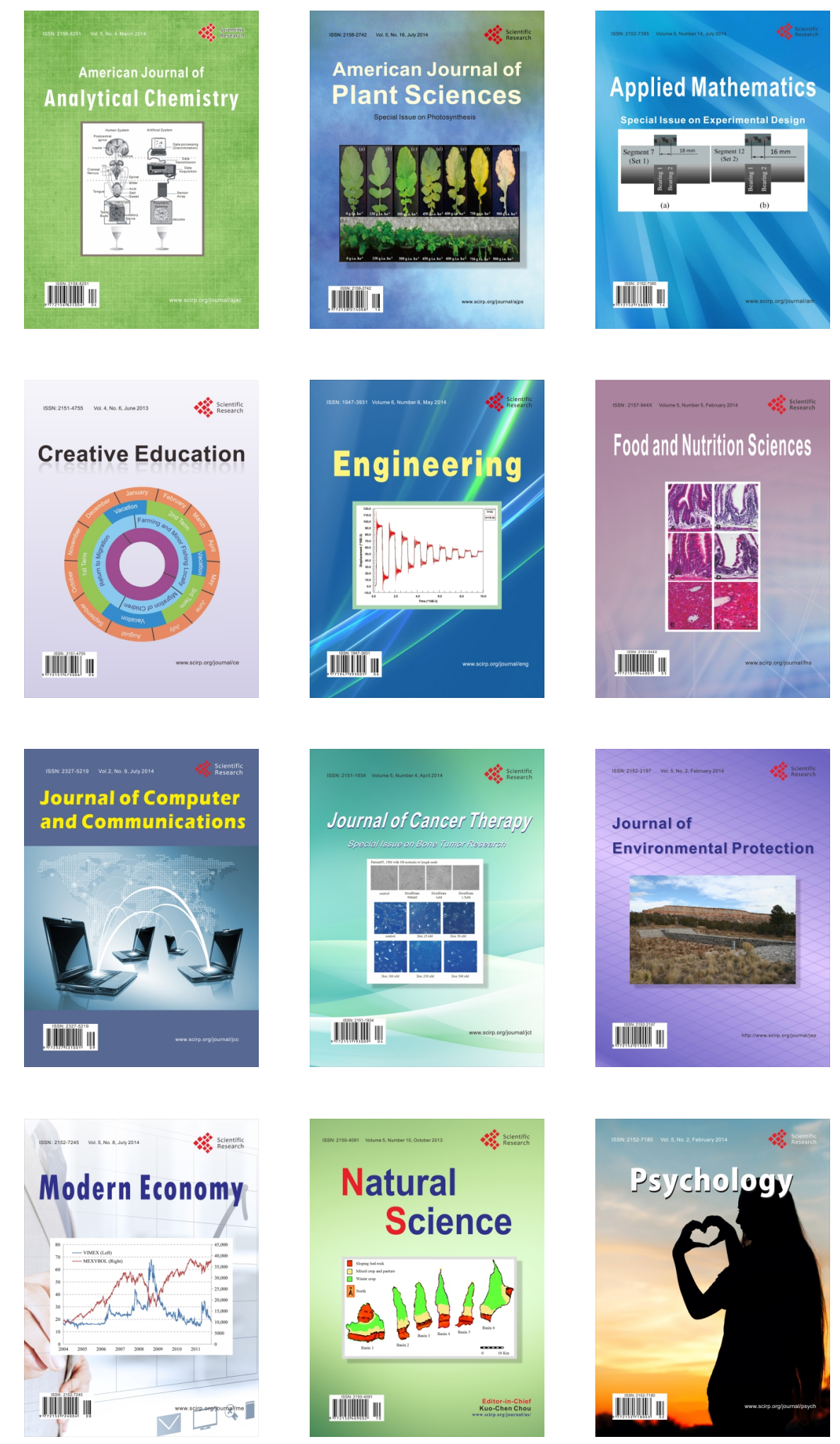